\title{
Evaluation of Esophageal Functions by Manometry in Iron Deficiency Anemia Patients
}

\author{
Pinar Kubilay $^{a}$, Beyza Doganay ${ }^{\mathrm{b}}$, Mehmet Bektas ${ }^{\mathrm{c}, \mathrm{d}}$
}

\begin{abstract}
Background: The aim of this study was to investigate whether any esophageal motor dysfunction exists in patients with iron deficiency anemia (IDA).

Methods: The study included 39 patients (34 women, mean age: $44.17 \pm 14.21$ years) who met WHO diagnostic criteria for IDA. An additional 30 functional dyspepsia patients were also included as a control group. Esophageal motility testing was performed; esophagus contraction amplitude, peak velocity, contraction time, lower esophageal sphincter (LES) resting pressure, LES relaxation, and LES relaxation duration were assessed.

Results: A majority (76.4\%) of patients had at least one IDA symptom, such as reflux, chest pain, or dysphagia. Manometric findings in IDA patients vs. controls were as follows: mean LES resting pressure ( $\mathrm{mm} \mathrm{Hg}$ ): $25.41 \pm 11.67$ vs. $19.96 \pm 6.58(\mathrm{P}=0.025)$; mean esophageal contraction amplitude $(\mathrm{mm} \mathrm{Hg}): 61.61 \pm 24.21 \mathrm{vs} .63 .23 \pm 18.86$ $(\mathrm{P}=0.764)$; mean LES relaxation duration ( $\mathrm{s}, \mathrm{x} \pm \mathrm{SD})$ : $5.33 \pm 1.61 \mathrm{vs}$. $8.75 \pm 1.86(\mathrm{P}=0.000)$; mean LES relaxation (\%): $93.30 \pm 9.88$ vs. $95.53 \pm 5.81(\mathrm{P}=0.278)$; mean peak velocity $(\mathrm{cm} / \mathrm{s}): 12.67 \pm 37.95$ vs. $3.50 \pm 1.63(\mathrm{P}=0.191)$. Esophageal dysmotility was found in 11 (28.2\%) IDA patients. Non-specific esophageal motor disorder was found in three patients, hypomotility of the esophagus was found in three patients, achalasia was found in two patients, hypertensive LES was found in two patients, and hypotensive LES was found in one patient.
\end{abstract}

Conclusion: LES resting pressure was higher and LES relaxation duration was shorter in patients with IDA. Esophageal dysmotility was present in $28.2 \%$ of the patients with IDA A little more than half of

Manuscript submitted May 10, 2017, accepted June 12, 2017

aDepartment of Internal Medicine, Ankara University School of Medicine, Ankara, Turkey

bDepartment of Biostatistics, Ankara University School of Medicine, Ankara, Turkey

'Department of Gastroenterology, Ankara University School of Medicine, Ankara, Turkey

${ }^{\mathrm{d} C o r r e s p o n d i n g ~ A u t h o r: ~ M e h m e t ~ B e k t a s, ~ D e p a r t m e n t ~ o f ~ G a s t r o e n t e r o l o g y, ~}$ Ankara University School of Medicine, Ibn-i Sina Hospital, Sihhiye, Ankara 06100, Turkey. Email: mbektas@medicine.ankara.edu.tr

doi: https://doi.org/10.14740/gr850w patients had dysphagia symptoms. IDA may contribute to esophageal motility dysfunction and esophageal symptoms.

Keywords: Iron deficiency anemia; Esophageal function

\section{Introduction}

Iron deficiency anemia (IDA) is the most common form of anemia worldwide, and it is more prevalent in women than in men due to iron loss from menstruation and pregnancy. Low serum iron, low transferrin saturation, and high total iron binding capacity are diagnostic signs of iron deficiency [1]. Ferritin reflects iron stores and is the most accurate test for diagnosing IDA [2].

Iron is a major component of myoglobin, cytochromes, catalase, and peroxidase. Decreased protein levels and enzymatic activity have been observed in iron deficiency for cytochrome $\mathrm{c}$ in the muscle and intestine, cytochrome oxidase in the buccal mucosa and intestine, and myoglobin and alphaglycerophosphate oxidase in muscle $[3,4]$. Although the etiology of web formation, esophageal stricture, and the presence of dysphagia is not known, the most probable mechanism is iron deficiency leading to the rapid loss of iron-dependent enzymes and mucosal degeneration $[5,6]$.

There are not enough data about the effect of esophageal function, and it has only been evaluated in a limited number of trials including very few patients. In a study including 19 Plummer-Vinson patients, three underwent esophageal manometric assessment. In these three patients, the pressure in the hypopharyngeal cavity was low and contraction amplitude in the pharyngeal muscles after swallowing was decreased [7]. In another study of 12 IDA patients, a decrease in esophageal contractions and an increase in esophageal transit duration were found [8]. The aim of this study was to investigate the effect of IDA on LES pressure and esophageal motility.

\section{Patients and Methods}

Thirty-nine patients with IDA over 18 years of age were enrolled in the study. Thirty-four of the patients were women with a mean age of $44.17 \pm 14.21$ years (min.: 21 ; max.: 79). The study was conducted from 2010 to 2014 in the Ankara University Faculty of Medicine, Department of Internal Medi- 
cine, Department of Gastroenterology Motility Laboratory. The diagnosis of IDA was established according to WHO criteria (hemoglobin $(\mathrm{Hb})<12 \mathrm{~g} / \mathrm{dL}$ in women and $<13 \mathrm{~g} / \mathrm{dL}$ in men, ferritin $<30 \mathrm{ng} / \mathrm{mL}$ ) [9]. Patients with systemic diseases that could alter esophageal functions, hemorrhaging within 3 months, or chronic disease anemia were excluded.

All patients' blood count, ferritin, serum iron, total iron binding capacity, transferrin saturation, and vitamin $B_{12}$ tests were investigated within 1 month prior to motility testing. Thirty patients with functional dyspepsia, who were diagnosed according to Rome II criteria, were also included in the study as a control group [10]. Patients were asked if they had esophageal symptoms such as dysphagia, reflux, and chest pain as well as for the duration of their anemia. The distinction between oropharyngeal and esophageal dysphagia was made by questioning the symptoms of the patients. All patients underwent upper gastrointestinal endoscopic examination and esophageal motility testing on separate days. Endoscopic examinations were performed by one of the investigators using a standard video gastroscope (Fujinon, Tokyo, Japan).

\section{Manometry testing}

Esophageal manometry was performed using a single catheter containing eight microperfusion state pressure transducers spaced at $5 \mathrm{~cm}$ intervals and attached to an online computer (MMS, Medical Measurement Systems, The Netherlands). Patients came to the laboratory after at least $8 \mathrm{~h}$ of fasting. The eight-channel catheter was lubricated, passed nasally, and advanced into the stomach. A slow station pull-through was performed at $1 \mathrm{~cm}$ increments. Once the lower esophageal sphincter (LES) was profiled, the distal pressure transducer, which included four lumens, was placed in the high-pressure zone of the LES. Proximal pressure transducers were located 5, 10, 15 , and $20 \mathrm{~cm}$ above the LES. A series of 10 wet swallows (with $5 \mathrm{~mL}$ water bolus) were given at $30 \mathrm{~s}$ intervals. Each contraction was recorded and then analyzed by a computerized software system (MMS, Medical Measurement Systems, The Netherlands) for amplitude, contraction, and velocity. The catheter assembly was then located $5 \mathrm{~cm}$ above the LES for assessment of the pressure from the distal part $(5$ and $10 \mathrm{~cm})$ of the esophagus. Average LES resting pressure (reference $6-25$ $\mathrm{mm} \mathrm{Hg}$ ), percentage of wet swallowing over peristaltic waves (reference N: $80 \%$ ), and average esophagus corpus amplitude (reference $30-160 \mathrm{~mm} \mathrm{Hg}$ ) were determined. LES relaxation and residual pressures were also recorded. The conventional classification of esophageal motility was used for diagnosis of abnormal esophageal function [11]. This classification is summarized below. 1) Normal: normal velocity; normal peristaltic amplitude; $\geq 7$ peristaltic contractions with an intact wave progression (amplitude $>30 \mathrm{~mm} \mathrm{Hg}$ ). 2) Achalasia: absent distal peristalsis; incomplete LES relaxation (residual pressure > $8 \mathrm{~mm} \mathrm{Hg}$ ); elevated resting LES pressure $(>45 \mathrm{~mm} \mathrm{Hg}$ ). 3) Diffuse (or distal) esophageal spasm: simultaneous contractions ( $\geq 20 \%$ wet swallows); intermittent peristalsis; repetitive contractions ( $\geq 3$ peaks); prolonged duration contractions ( $>$ 6 s). 4) Hypercontracting esophagus: hypertensive peristalsis (nutcracker esophagus) (increased distal peristaltic amplitude
Table 1. Clinical and Laboratory Features of Patients With IDA

\begin{tabular}{ll}
\hline Gender $(\mathrm{F} / \mathrm{M}), \mathrm{n}(\%)$ & $34 / 5(87.2 \% / 12.8 \%)$ \\
Mean age (years) & $44.17 \pm 2.27$ \\
Ferritin $(\mathrm{ng} / \mathrm{mL})$ & $9.46 \pm 6.75$ \\
$\mathrm{MCV}\left(\mu \mathrm{m}^{3}\right)$ & $81.52 \pm 6.42$ \\
$\mathrm{Hb}(\mathrm{g} / \mathrm{L})$ & $11.42 \pm 0.86$ \\
Serum iron $(\mu \mathrm{g} / \mathrm{dL})$ & $42.51 \pm 20.80$ \\
Serum iron binding capacity $(\mu \mathrm{g} / \mathrm{dL})$ & $402.97 \pm 48.49$ \\
$\%$ Transferrin saturation & $11.58 \pm 5.81$ \\
Hb $<11(\mathrm{~g} / \mathrm{L}), \mathrm{n}(\%)$ & $13(33.3 \%)$ \\
Anemia duration $($ months $)$ & $34.37 \pm 24.65$ \\
Dysphagia, $\mathrm{n}(\%)$ & $21(53.8 \%)$ \\
\hline
\end{tabular}

(mean value $>220 \mathrm{~mm} \mathrm{Hg}$ ); increased distal peristaltic duration (mean value $>6 \mathrm{~s}$ )); hypertensive LES (resting LES pressure $>45 \mathrm{~mm} \mathrm{Hg}$; may be incomplete LES relaxation (residual pressure $>8 \mathrm{~mm} \mathrm{Hg}$ )). 5) Hypocontracting esophagus: ineffective esophageal motility (esophageal hypomotility) (increased low amplitude peristalsis ( $\geq 50 \%$ wet swallows); low distal peristaltic amplitude $(<30 \mathrm{~mm} \mathrm{Hg}))$; hypotensive LES (resting LES pressure $<10 \mathrm{~mm} \mathrm{Hg}$ ).

The term non-specific esophageal motility disorder was used when a patient with dysphagia and/or chest pain had abnormal findings on esophageal motility tracing but did not fulfill the criteria for other diagnosis.

This study was approved by the Institutional Review Board of Ankara University Medical School, and all patients provided signed informed consent before entering the study. Statistical analysis was performed with SPSS 11.5 for Windows (SPSS Inc., Chicago, IL). Metric values were expressed as mean \pm standard deviation (SD) and median (minimummaximum). The differences between the groups were evaluated by Student's $t$-test, one-way ANOVA, Mann-Whitney U test, and Kruskal-Wallis test, depending on the normality of the data. $P$ value less than 0.05 was considered to be significant.

\section{Results}

Between 2010 and 2014, 39 patients with IDA were enrolled in the study. Hemoglobin value, ferritin value, and anemia duration of the patients were $11.42 \pm 0.86 \mathrm{~g} / \mathrm{dL}(9.7-12.9$ $\mathrm{g} / \mathrm{dL}), 9.46 \pm 6.75 \mathrm{ng} / \mathrm{mL}(2-30 \mathrm{ng} / \mathrm{mL})$ and $34.37 \pm 24.65$ months (6 - 96 months), respectively. More than three-quarters $(76.4 \%)$ of the patients had at least one of the symptoms (reflux, chest pain, or dysphagia). Most commonly seen esophageal symptom was dysphagia (21 patients, 53.6\%). Celiac disease was also present in three patients, and all of these three patients had dysphagia. The IDA patient characteristics are summarized in Table 1 . The control group consisted of 30 patients: $18(60 \%)$ women and $12(40 \%)$ men. The mean age was 43.50 years $( \pm 10.93)$. There was no significant difference between the mean age $(44.17 \pm 2.27$ years vs. $43.50 \pm 10.93$ years, $\mathrm{P}=0.829$ ) of patients with IDA compared to those in 
Table 2. Manometric Findings in Patients With IDA Compared to Control Group

\begin{tabular}{llll} 
& IDA & Functional dyspepsia & P \\
\hline LES resting pressure $(\mathrm{mm} \mathrm{Hg})$ & $25.41 \pm 11.67$ & $19.96 \pm 6.58$ & 0.025 \\
LES relaxation (\%) & $93.30 \pm 9.88$ & $95.53 \pm 5.81$ & 0.278 \\
LES relaxation duration (s) & $5.33 \pm 1.61$ & $8.75 \pm 1.86$ & 0.000 \\
Esophagus contraction amplitude $(\mathrm{mm} \mathrm{Hg})$ & $61.61 \pm 24.21$ & $63.23 \pm 18.86$ & 0.764 \\
Peak velocity $(\mathrm{cm} / \mathrm{s})$ & $12.67 \pm 37.95$ & $3.50 \pm 1.63$ & 0.191 \\
\hline
\end{tabular}

the control group.

\section{Manometric findings}

LES resting pressure was $25.41 \pm 11.67 \mathrm{~mm} \mathrm{Hg}$, LES relaxation $(\%)$ was $93.30 \pm 9.88$, LES relaxation duration was $5.33 \pm 1.61 \mathrm{~s}$, and mean esophagus contraction amplitude was $61.61 \pm 24.21 \mathrm{~mm} \mathrm{Hg}$ in IDA patients. In the control group, these parameters were $19.96 \pm 6.58 \mathrm{~mm} \mathrm{Hg}, 95.53 \pm 5.81 \%$, $8.75 \pm 1.86 \mathrm{~s}$, and $63.23 \pm 18.86 \mathrm{~mm} \mathrm{Hg}$, respectively. When patients with IDA were compared to functional dyspepsia patients, LES resting pressure was higher $(\mathrm{P}=0.025)$ and LES relaxation duration was shorter $(\mathrm{P}=0.000)$. There was no statistically significant difference between LES relaxation $(\%)(\mathrm{P}$ $=0.278)$, mean esophageal contraction amplitude $(\mathrm{P}=0.764)$, and velocity $(\mathrm{P}=0.191)$ (Table 2$)$.

Esophageal dysmotility was detected in 11 of 39 patients with IDA (non-specific esophagus motor disease: three patients; achalasia: two patients; hypertensive LES: two patients; esophageal hypomotility: three patients; hypotensive LES: one patient), whereas none of the functional dyspepsia patients had any abnormalities. Nine $(81.9 \%)$ of these patients had dysphagia and two (17.1\%) had reflux symptoms.

Twenty-one IDA patients had dysphagia symptoms. The mean age, anemia duration, mean $\mathrm{Hb}$, mean ferritin, esophageal motility impairment, mean LES resting pressure (mm $\mathrm{Hg}$ ), median LES relaxation (\%), mean LES relaxation duration $(\mathrm{s}, \mathrm{x} \pm \mathrm{SD})$, mean esophagus contraction amplitude $(\mathrm{mm} \mathrm{Hg})$, and mean peak velocity $(\mathrm{cm} / \mathrm{s}, \mathrm{x} \pm \mathrm{SD})$ were not significantly different in patients with dysphagia compared to patients without dysphagia $(46.95 \pm 16.42$ years vs. 40.94 \pm 10.67 years, $\mathrm{P}=0.192 ; 32.57 \pm 26.69$ months vs. $36.90 \pm$ 22.62 months, $\mathrm{P}=0.681 ; 11.52 \pm 0.95 \mathrm{~g} / \mathrm{dL}$ vs. $11.29 \pm 0.74$ $\mathrm{g} / \mathrm{dL}, \mathrm{P}=0.405 ; 8.90 \pm 5.89 \mathrm{ng} / \mathrm{mL}$ vs. $10.11 \pm 7.76 \mathrm{ng} / \mathrm{mL}$, $\mathrm{P}=0.585 ; 38.1 \%$ vs. $16.7 \%, \mathrm{P}=0.130 ; 24.80 \pm 11.53 \mathrm{~mm}$ $\mathrm{Hg}$ vs. $26.11 \pm 12.13 \mathrm{~mm} \mathrm{Hg}, \mathrm{P}=0.734 ; 90.76 \pm 12.79 \%$ vs. $96.27 \pm 2.92 \%, \mathrm{P}=0.082 ; 5.48 \pm 1.91 \mathrm{~s}$ vs. $5.15 \pm 1.20 \mathrm{~s}, \mathrm{P}=$ $0.531 ; 61.28 \pm 23.39 \mathrm{~mm} \mathrm{Hg}$ vs. $62.00 \pm 25.82 \mathrm{~mm} \mathrm{Hg}, \mathrm{P}=$ $0.928 ; 20.54 \pm 52.38 \mathrm{~cm} / \mathrm{s}$ vs. $4.36 \pm 1.36 \mathrm{~cm} / \mathrm{s}, \mathrm{P}=0.199$, respectively) (Table 3 ).

The IDA patients were divided into two groups based on their $\mathrm{Hb}$ values $(\leq 11 \mathrm{~g} / \mathrm{dL}$ or $>11 \mathrm{~g} / \mathrm{dL})$. Hb values under $11 \mathrm{~g} /$ $\mathrm{dL}$ were detected in 13 of 39 patients with IDA. There was no significant difference between dysphagia (\%) (53.8 vs. 53.8, $\mathrm{P}=0.632)$, mean anemia duration (month) $(30.30 \pm 24.99$ vs. $37.28 \pm 24.92, \mathrm{P}=0.506)$, esophageal motility impairment $(\%)$ (38.5 vs. 23.1, $\mathrm{P}=0.262)$, mean LES resting pressure ( $\mathrm{mm} \mathrm{Hg}$ ) $(28.38 \pm 14.18$ vs. $23.92 \pm 10.19, \mathrm{P}=0.266)$, median LES relaxation $(\%)(93.23 \pm 8.61$ vs. $93.34 \pm 10.63, \mathrm{P}=0.973)$, mean

Table 3. Manometry Findings in Dysphagia Positive or Negative Patients Who Have IDA

\begin{tabular}{|c|c|c|c|}
\hline & Dysphagia positive $(n=21)$ & Dysphagia negative $(n=18)$ & $\mathbf{P}$ \\
\hline Mean age (years) & $46.95 \pm 16.42$ & $40.94 \pm 10.67$ & 0.192 \\
\hline Anemia duration (months) & $32.57 \pm 26.69$ & $36.90 \pm 22.62$ & 0.681 \\
\hline LES resting pressure (mm Hg) & $24.80 \pm 11.53$ & $26.11 \pm 12.13$ & 0.734 \\
\hline LES relaxation $(\%)$ & $90.76 \pm 12.79$ & $96.27 \pm 2.92$ & 0.082 \\
\hline Esophagus contraction amplitude ( $\mathrm{mm} \mathrm{Hg}$ ) & $61.28 \pm 23.39$ & $62.00 \pm 25.82$ & 0.928 \\
\hline Peak velocity $(\mathrm{cm} / \mathrm{s})$ & $20.54 \pm 52.38$ & $4.36 \pm 1.36$ & 0.199 \\
\hline Mean $\mathrm{Hb}(\mathrm{g} / \mathrm{dL})$ & $11.52 \pm 0.95$ & $11.29 \pm 0.74$ & 0.405 \\
\hline Mean ferritin (ng/mL) & $8.90 \pm 5.89$ & $10.11 \pm 7.76$ & 0.585 \\
\hline $\operatorname{MCV}\left(\mu \mathrm{m}^{3}\right)$ & $83.43 \pm 5.10$ & $79.30 \pm 7.18$ & 0.043 \\
\hline Serum iron binding capacity $(\mu \mathrm{g} / \mathrm{dL})$ & $412.09 \pm 41.52$ & $392.33 \pm 54.82$ & 0.209 \\
\hline
\end{tabular}


Table 4. Manometry Findings in IDA Patients With Hemoglobin Levels Equal to or Above 11 and Hemoglobin Levels Below 11

\begin{tabular}{llll}
\hline & Hb $\leq \mathbf{1 1}(\mathbf{n}=\mathbf{1 3})$ & Hb $>\mathbf{1 1}(\mathbf{n}=\mathbf{2 6})$ & P \\
\hline Dysphagia (n= 21), $\mathrm{n}(\%)$ & $7(53.8 \%)$ & $14(53.8 \%)$ & 0.632 \\
Anemia duration (months) & $30.30 \pm 24.99$ & $37.28 \pm 24.92$ & 0.506 \\
Motility impairment ( $=11), \mathrm{n}(\%)$ & $5(38.5 \%)$ & $6(23.1 \%)$ & 0.262 \\
LES resting pressure (mm Hg) & $28.38 \pm 14.18$ & $23.92 \pm 10.19$ & 0.266 \\
LES relaxation (\%) & $93.23 \pm 8.61$ & $93.34 \pm 10.63$ & 0.973 \\
LES relaxation duration (s) & $5.30 \pm 1.40$ & $5.35 \pm 1.73$ & 0.929 \\
Esophagus contraction amplitude (mm Hg) & $69.46 \pm 28.88$ & $57.69 \pm 21.04$ & 0.155 \\
Peak velocity (cm/s) & $3.83 \pm 0.79$ & $46.75 \pm 9.54$ & 0.304 \\
\hline
\end{tabular}

LES relaxation duration $(\mathrm{s}, \mathrm{x} \pm \mathrm{SD})(5.30 \pm 1.40$ vs. $5.35 \pm$ $1.73, \mathrm{P}=0.929)$, mean esophagus contraction amplitude ( $\mathrm{mm}$ $\mathrm{Hg})(69.46 \pm 28.88$ vs. $57.69 \pm 21.04, \mathrm{P}=0.155)$, and mean peak velocity $(\mathrm{cm} / \mathrm{s}, \mathrm{x} \pm \mathrm{SD})(3.83 \pm 0.79$ vs. $46.75 \pm 9.54, \mathrm{P}=$ 0.304 ) in patients with $\mathrm{Hb}$ values under $11 \mathrm{~g} / \mathrm{dL}$ compared to those with $\mathrm{Hb}$ values over $11 \mathrm{~g} / \mathrm{dL}$ (Table 4).

\section{Discussion}

IDA is the most common form of anemia worldwide, and it is more common in women than in men due to iron loss from menstruation and pregnancy. In South America and Asia, the iron deficiency rate is reported as $1.9-14 \%$ in men and $15-64 \%$ in women [12]. In our study, three-quarters of 39 IDA patients experienced esophageal symptoms such as reflux, chest pain, and dysphagia. The most common esophageal symptom was dysphagia, with an occurrence rate of $53.8 \%$. All patients with dysphagia had oropharyngeal dysphagia. No esophageal web or stricture was observed in any of the patients with endoscopic or radiologic examination.

The etiology of esophageal strictures, webs, and dysphagia in iron deficiency cases is not clearly understood, but it has been suggested that a decrease in iron-dependent enzymes leading to mucosal degeneration may be the cause $[5,6]$. Plummer was the first to describe the relationship between IDA and the esophagus in 1912 [13]. It was shown that cervical esophageal webs, which are present in Plummer-Vinson or PatersonBrown-Kelly syndrome, are associated with IDA.

In a study by Okamura et al including 19 patients, all of whom had dysphagia symptoms, esophageal webs were shown in the esophagographies of all patients, but no membranous structures were detected in 13 patients who underwent endoscopic examination. In three of these 19 patients, manometric analyses were performed, and the pressure measured in the hypopharyngeal cavity was low. In those three patients, the hypopharyngeal pressure normalized after iron replacement. In 15 of the 19 patients who were followed up long term, dysphagia symptoms disappeared completely with iron supplementation, and it was shown that shrinking or disappearance of the esophageal web occurred after the dysphagia symptoms disappeared. The authors concluded that the primary cause of dysphagia could not be the web, as dysphagia disappeared in the first and second months of treatment while the decrease in web size occurred after the second month of treatment [7].

Dantas et al evaluated esophageal function in 12 IDA patients (11 females and one male). Esophageal manometry was performed for 11 patients, and the esophageal transit time was studied by scintigraphic methods in 10 of these patients. In this study, no significant difference between oropharyngeal transit times was found between the IDA patients and the control group. However, there was a statistically significant increase in the proximal and middle esophageal transit time in IDA patients. The LES resting pressure, LES relaxation time, and velocity in IDA patients were no different from those in the control group. The esophageal body contraction amplitude and contraction time 9 and $15 \mathrm{~cm}$ above the LES was significantly lower in the IDA patients when compared to the control group [8].

In another study published by the same researchers, 12 IDA patients were evaluated by esophageal manometry. It was stated that the contraction time and amplitude in the esophagus was low. When the initial five consecutive and final five consecutive swallow amplitudes, velocities, and times were compared, there was no significant difference between them [14].

In our study, esophageal body functions and LES functions were evaluated by manometry in 39 IDA patients and 30 functional dyspepsia patients (control group). In the IDA group, the mean LES resting pressure $(\mathrm{mm} \mathrm{Hg})$ was $25.41 \pm$ 11.67, the LES relaxation percentage $(\%)$ was $93.30 \pm 9.88$, the mean LES relaxation time was $5.33 \pm 1.61 \mathrm{~s}$, the mean esophageal body contraction amplitude $(\mathrm{mm} \mathrm{Hg})$ was $61.61 \pm$ 24.21 , and the mean velocity $(\mathrm{cm} / \mathrm{s})$ was $12.67 \pm 37.95$. In the control group, these parameters were reported as $19.96 \pm 6.58$ $\mathrm{mm} \mathrm{Hg}, 95.53 \pm 5.81 \%, 8.75 \pm 1.86 \mathrm{~s}, 63.23 \pm 18.86 \mathrm{~mm} \mathrm{Hg}$, and $3.50 \pm 1.63 \mathrm{~cm} / \mathrm{s}$, respectively. When both groups were compared, the LES resting pressure was higher and the LES relaxation time was shorter in the IDA group than in the functional dyspepsia group.

In our study, esophageal motility disorders were identified in $11(28.2 \%)$ of the 39 IDA patients. Non-specific esophageal motility disorder was shown in three patients, achalasia in two patients, hypertensive LES in two patients, esophageal hypomotility in three patients, and hypotensive LES in one patient. Complaints of dysphagia were present in nine of 11 patients $(81.9 \%)$, and two patients $(17.1 \%)$ complained of reflux. There is no information in the literature about esophagus motility disorders that may be present in IDA patients. In this 
regard, our study is capable of contributing to the relevant literature.

Case reports of celiac disease patients presenting with Plummer-Vinson syndrome are present in the literature [1518]. In a study evaluating the association between cervical esophageal webs and celiac disease including 21 dysphagia and esophageal web patients, IDA was identified in 18 of the patients, while five patients were diagnosed with celiac disease by tissue transglutaminase activity and duodenal biopsy results. IDA was present in the five patients diagnosed with celiac disease, and consequently it was recommended that esophageal web and IDA patients should be screened for celiac disease [19]. In our study, celiac disease was identified histopathologically in only three of the duodenal biopsies obtained during the upper gastrointestinal endoscopies of IDA patients. The diagnoses were verified with serological tests. In our three patients with IDA plus celiac disease, dysphagia was present, but an esophageal motility disorder was present in only one patient. Esophageal body contraction amplitude was found to be lower in this patient. In a previous study including 18 celiac patients with esophageal symptoms, patients were studied by manometry, and motor disorders such as nutcracker esophagus and hypotonic LES associated with simultaneous contractions were found in $67 \%$ of the patients [20].

It is unknown whether esophageal functions change in accordance with the degree of IDA. With a goal of understanding this issue, patients in the IDA group were classified based on having $\mathrm{Hb}$ levels higher or lower than $11 \mathrm{~g} / \mathrm{dL}$. No statistically significant difference in the presence of dysphagia, duration of anemia, presence of motility disorders, LES pressure, relaxation percentage, relaxation time, esophageal contraction amplitude, and velocity parameters was reported. In addition, the IDA patients were split into two groups according to the presence of dysphagia; no difference was found in the same parameters between the groups.

Our study is limited in some aspects. 1) Although all IDA patients had oropharyngeal dysphagia symptoms, the upper esophageal sphincter was not evaluated with a solid-state catheter. 2) High-resolution manometry systems were not used. 3) Video cineradiography was not performed in the patients with oropharyngeal dysphagia symptoms.

In conclusion, dysphagia symptoms were present in more than half of the patients, independent of the degree of IDA. In manometric evaluations of the IDA patients, the LES resting pressure was increased while the LES relaxation time was decreased. In addition, in approximately one-quarter of the patients, esophageal motility disorders were present. Taking into account of this information, our study suggests that IDA can affect esophageal function. There are only a limited number of trials including very few patients present in the literature. Thus, prospective studies with larger patient series are necessary.

\section{Abbreviations}

IDA: iron deficiency anemia; LES: lower esophagus sphincter; IEM: ineffective esophageal motility

\section{References}

1. Johnson-Wimbley TD, Graham DY. Diagnosis and management of iron deficiency anemia in the 21 st century. Therap Adv Gastroenterol. 2011;4(3):177-184.

2. Goddard AF, James MW, McIntyre AS, Scott BB, British Society of G. Guidelines for the management of iron deficiency anaemia. Gut. 2011;60(10):1309-1316.

3. Hagler L, Askew EW, Neville JR, Mellick PW, Coppes RI Jr, Lowder JF Jr. Influence of dietary iron deficiency on hemoglobin, myoglobin, their respective reductases, and skeletal muscle mitochondrial respiration. Am J Clin Nutr. 1981;34(10):2169-2177.

4. Dallman PR, Schwartz HC. Myoglobin and cytochrome response during repair of iron deficiency in the rat. J Clin Invest. 1965;44(10):1631-1638.

5. Novacek G. Plummer-Vinson syndrome. Orphanet J Rare Dis. 2006;1:36.

6. Tahara T, Shibata T, Okubo M, Yoshioka D, Ishizuka T, Sumi K, Kawamura T, et al. A case of plummer-vinson syndrome showing rapid improvement of Dysphagia and esophageal web after two weeks of iron therapy. Case Rep Gastroenterol. 2014;8(2):211-215.

7. Okamura H, Tsutsumi S, Inaki S, Mori T. Esophageal web in Plummer-Vinson syndrome. Laryngoscope. 1988;98(9):994-998.

8. Miranda AL, Dantas RO. Esophageal contractions and oropharyngeal and esophageal transits in patients with iron deficiency anemia. Am J Gastroenterol. 2003;98(5):10001004.

9. Assessing the iron status of populations: report of a joint World Health Organization/Centers for Disease Control and Prevention technical consultation on the assessment of iron status at the population level, Geneva, Switzerland, 6-8 April 2004. Geneva: World Health Organization, Centers for Disease Control and Prevention; 2005.

10. Drossman DA. The functional gastrointestinal disorders and the Rome II process. Gut. 1999;45(Suppl 2):II1-5.

11. Castell DO. Esophageal motility disorders: Clinical manifestations, diagnosis, and management. In: UpToDate, Waltham MA. (Accessed on June 7, 2017).

12. Beutler E. Disorders of iron metabolism. In: Lichtman MA, Kipps TJ, Seligsohn U, Kaushansky K, Prchal JT, (Eds.). Williams Hematology, 8th ed. The McGraw-Hill Companies. 2010.

13. Plummer HS. Diffuse dilatation of the esophagus without anatomic stenosis (cardiospasm): a report of ninety-one cases. JAMA. 1912;LVIII:2013-2015.

14. Dantas RO, Miranda AL. Sequential swallows have no influence on esophageal contractions of patients with iron deficiency anemia. Arq Gastroenterol. 2004;41(1):27-32.

15. Sood A, Midha V, Sood N, Bansal M. Paterson Kelly syndrome in celiac disease. J Assoc Physicians India. 2005;53:991-992.

16. Dickey W, McConnell B. Celiac disease presenting as the Paterson-Brown Kelly (Plummer-Vinson) syndrome. Am J Gastroenterol. 1999;94(2):527-529. 
17. Malhotra P, Kochhar R, Varma N, Kumari S, Jain S, Varma S. Paterson-Kelly syndrome and celiac disease - a rare combination. Indian J Gastroenterol. 2000;19(4):191192.

18. Hefaiedh R, Boutreaa Y, Ouakaa-Kchaou A, Kochlef A, Elloumi H, Gargouri D, Kharrat J, et al. Plummer Vinson syndrome association with coeliac disease. Arab J Gas- troenterol. 2013;14(4):183-185.

19. Sinha SK, Nain CK, Udawat HP, Prasad KK, Das R, Nagi B, Singh K. Cervical esophageal web and celiac disease. J Gastroenterol Hepatol. 2008;23(7 Pt 1):1149-1152.

20. Usai P, Bassotti G, Usai Satta P, Cherchi M, Plesa A, Boy F, Morelli A, et al. Oesophageal motility in adult coeliac disease. Neurogastroenterol Motil. 1995;7(4):239-244. 